\title{
Regeneration of the liver after hepatectomy in egyptian patients with schistosomal periportal fibrosis
}

\author{
Yasser Hamza, MD FRCS; Galal Abul Nagah, MD, FRCS; \\ Habashi El-Hammady, MD
}

Departments of Surgery, University of Alexandria, Alexandria, Egypt.

\author{
Correspondence: \\ Yasser Hamza, MD FRCS: Assistant Professor of Surgery, \\ University of Alexandria, Azarita, Alexandria, Egypt. \\ Tel: 0122375287 - 035463815 \\ E-mail:hamzay3@hotmail.com
}

\begin{abstract}
Aim: The aim of this work was to assess the safety of liver resection in bilharzial patients with special attention to the ability of the bilharzial liver to regenerate.

Methods: The study included patients with liver mass indicated for resection. Patients with pathologically proved pure bilharzeal hepatic fibrosis and who fit in Child-Pugh class A or B were selected. Patients underwent liver resection. They were followed up for one year. They were examined serially for their liver functions and liver volumetry.

Results: Forty eight patients had liver resection. Of them, 16 had pure bilharzeal fibrosis. The mean age was $59 \pm 14$ years. There were eight right hepatectomies, three left lateral segementectomies, two left hepatectomies, two non-anatomical resections (for cancer gall bladder) and one IVth segmentectomy. Mean operating time was $155 \pm 73$ minutes. Mean blood loss was $430 \pm 720.72 \mathrm{mls}$. There were neither operative complications nor mortalities. Mean hepatic volumetry was $854.66 \pm 92.32,1003.68 \pm 123.68,1166.54 \pm 65.32$ and $1246.12 \pm 30.87 \mathrm{mls}$ at one, 12, 24 and 52 weeks postoperative respectively.

Conclusions: Resection in bilharzeal liver does not carry added operative risk. Bilharzeal liver has a considerably better regenerating power as compared to cirrhotic liver. It might therefore tolerate resection safely.

Key words: Liver resection, volume regeneration, bilharziasis.
\end{abstract}

\section{Introduction:}

Bilharzial hepatic fibrosis is the commonest cause of portal hypertension in Egypt. ${ }^{1}$ Portal hypertension is generally defined as a portal vein pressure above $10 \mathrm{mmHg}{ }^{2}$ Cirrhosis is the main pathology that causes portal hypertension. Cirrhosis is defined as diffuse nodulation resulting from fibrous bands subdividing the liver into regeneration nodules. ${ }^{3}$ Non cirrhotic portal hypertension is caused by schistosomiasis (bilharziasis) as well as a variety of conditions including: idiopathic portal hypertension (IPH), non-cirrhotic portal fibrosis and extrahepatic portal venous thrombosis, hepatic venous outflow tract obstruction, veno-occlusive disease and congenital hepatic fibrosis. The diagnosis of non-cirrhotic portal hypertension is usually made by abdominal ultrasound, upper gastrointestinal endoscopy, normal liver function tests and normal liver histology. 4

Liver resection is required for the management of a number of pathologies that affect the liver. ${ }^{5}$ The amount of liver tissue that can be safely resected depends on the total hepatic volume and the ability of the remaining liver to regenerate. ${ }^{6}$ Both features are severely impaired in cirrhotic liver. 7,8 
Bilharzial hepatic fibrosis has some resemblance to cirrhosis, yet it represents a different pathological process. ${ }^{9}$ A number of patients who are candidates for resection in Egypt will have bilharzial hepatic fibrosis, being a common endemic disease. To date, there has been very limited research that specifically addressed the effects of resection on bilharzial patients and the ability of bilharzial liver to regenerate. 10

\section{Aim:}

The aim of this work is to assess the safety of liver resection in bilharzial patients with special attention to the ability of the bilharzial liver to regenerate.

\section{Materials and methods:}

The study included 48 patients admitted for liver resection.

Patients were enrolled according to the following inclusion criteria:

- Past history of bilharzial infestation, positive shistozomal serology or positive urine or stool analysis for shistozomal ova.

- Negative serological markers for hepatitis B and $\mathrm{C}$.

- Child-Pugh class A or B.

- Ultrasonographic confirmation of periportal fibrosis with absence of cirrhotic changes.

- Histopathologic proof of pure shistosomal hepatic fibrosis. Selected patients had been proved to have pure bilharzial hepatic fibrosis by histopathological examination of either preoperative liver biopsy or by examining the post operative specimen. Patient personal approval to be enrolled in the study had been taken from all patients. This study has been approved by the Ethical Committee of the Faculty of Medicine University of Alexandria.

All patients were subjected to thorough clinical assessment and comprehensive laboratory workup including liver function tests, hepatitis B surface antigen (HBs Ag), anti-HBc and antibodies against hepatitis $\mathrm{C}$ virus (Anti HCV), serum alpha- fetoprotein (AFP) and carcino- embryonic antigen (CEA). Imaging of the liver included B-mode ultrasonography for determination of the degree of liver parenchymal insult (cirrhosis versus fibrosis). Tri-phasic C.T of the liver. Liver volumetry was calculated using CT data through image reformatting and manual and automated tracing- and liver biopsy. The appropriate pattern of resection was then performed. Data recorded included the type of hepatic resection performed, the technique used in resection, operative time, operative blood loss and complications.

Patients were reviewed at 1, 12, 24 and 52 weeks postoperatively. They underwent clinical check, liver function assessment, multi-slice $\mathrm{CT}$ of the liver and abdomen and liver volumetry. The percentage of liver regeneration was calculated.

\section{Results:}

During a period of two years, 48 patients had liver resections. Of those 16 patients fulfilled the inclusion criteria of the study. They had schistosomal hepatic fibrosis with varying degree of periportal fibrosis as diagnosed by histopathology. They were 14 males and two females. The age ranged between 45 and 72 with a mean of $59 \pm 14$ years. The indication for resection was hepatocellular carcinoma (HCC) in 7 patients, hemangioma in 4 , metastasis from colon cancer in 3 and carcinoma of gall bladder invading the liver parenchyma in two. Ten patients were Child's class A and six patients were Child's class B. None of the patients received oncologic treatment in the form chemo-embolisation, alcohol injection or radiofrequency prior to resection.

Patients had eight right hepatectomies Figures(1,2), three left lateral segementectomies, two left hepatectomies, two non-anatomical resections (for cancer gall bladder) and one IVth segmentectomy. Selective extrahepatic control of the inflow vessels was achieved in all cases. Control of hepatic veins was done intrahepatic starting by securing the small hepatic veins. Parenchymal dissection was done used Kelly clamp technique. Concomitant colectomy was performed in two cases.

Operative blood loss was $430 \pm 720.72 \mathrm{mls}$. Operating time ranged from $104 \mathrm{~min}$ to $225 \mathrm{~min}$ with a mean of $155 \pm 73$ minutes. There were neither operative complications nor mortalities. 
Postoperatively, six patients developed ascitis that was mild in four and moderate in two. All patients responded favorably to medical treatment. No patients developed hematemesis.

All patients attended the 12 weeks and 24 weeks follow-up visits. Eleven patients (11/15, $73.3 \%$ ) attended the 52 weeks visit Figure(3).
During follow-up visits, patients were clinically examined: There was no ascitis, no jaundice. Liver functions were within normal range Table(1). Patients were able to perform full duty work. Mean hepatic volumetry and the percentage increase in liver volume are shown in Table(2).

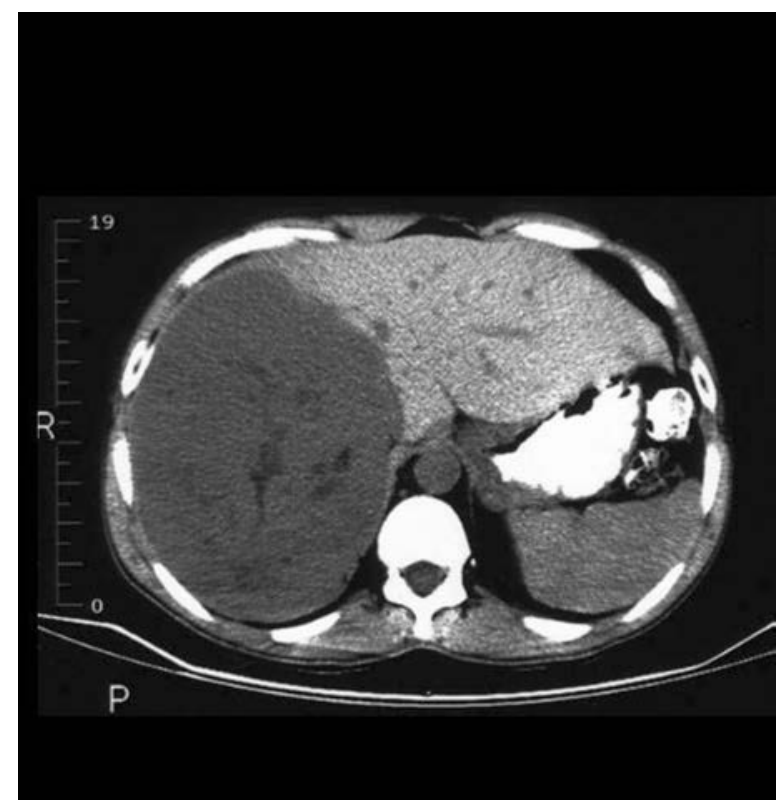

Figure (1): Preoperative CT of a large mass of the right lobe.

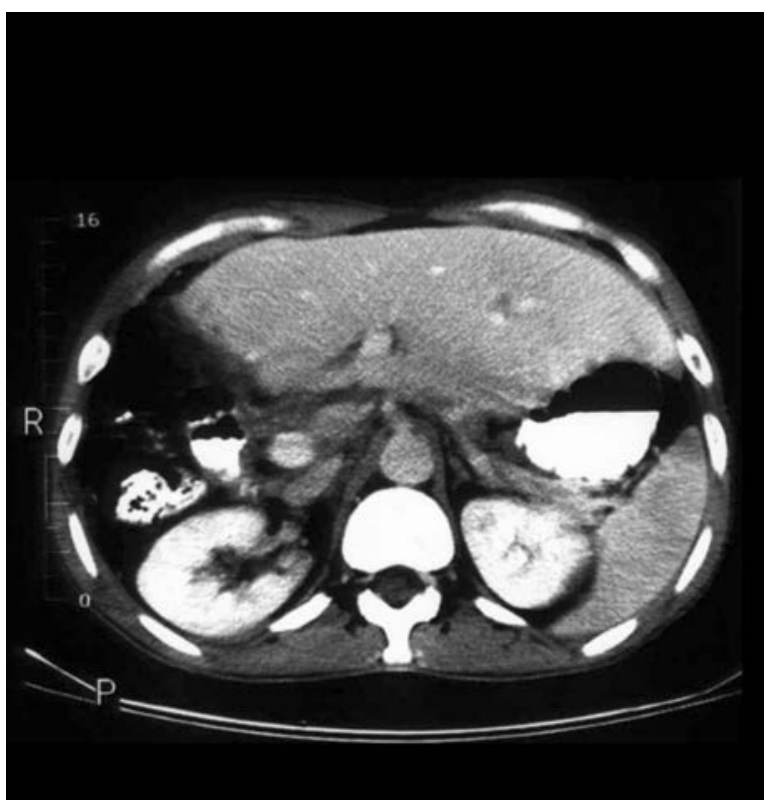

Figure (2): CT for the same patient in "figurel" one week after undergoing right hepatectomy.

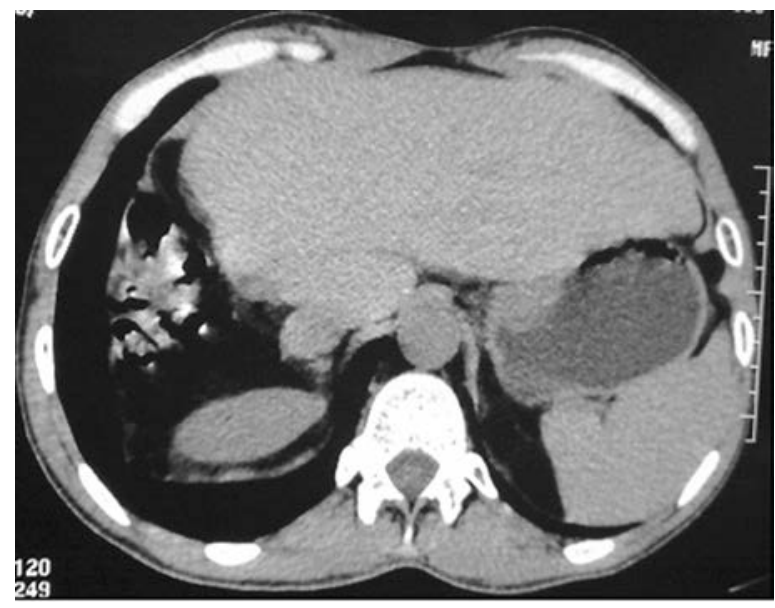

Figure (3): CT for the same patient in "figurel" 52 weeks after his right hepatectomy. 
Table (1): Mean values of liver functions postoperatively as compared to preoperative values.

\begin{tabular}{|l|c|c|c|c|c|}
\hline Liver function test & Bilirubin & AST & ALT & Prothrombin \% & Albumin \\
\hline Pre-operative & $0.82 \pm 0.32$ & $84 \pm 43.5$ & $74.8 \pm 43.8$ & $84 \pm 32$ & $3.43 \pm 0.9$ \\
\hline 12 weeks & $0.93 \pm 0.43$ & $63.7 \pm 63.3$ & $75 \pm 33.6$ & $86 \pm 22$ & $3.11 \pm 1.8$ \\
\hline 24 weeks & $0.92 \pm 0.24$ & $59.9 \pm 53.4$ & $63.5 \pm 27.2$ & $78 \pm 67$ & $3.43 \pm 2.32$ \\
\hline 52 weeks & $0.84 \pm 0.72$ & $57.8 \pm 62.3$ & $62.7 \pm 33.4$ & $81 \pm 83$ & $3.56 \pm 1.54$ \\
\hline
\end{tabular}

Table (2): Mean values of liver volumetry and the corresponding calculated percentage of increase liver volume.

\begin{tabular}{|l|c|c|}
\hline Duration after resection & Liver volumetry & \% increase in liver volume \\
\hline One week & $854.66 \pm 92.32$ & -- \\
\hline 12 weeks & $1003.68 \pm 123.68$ & $17.43 \pm 10.53 \%$ \\
\hline 24 weeks & $1166.54 \pm 65.32$ & $36.49 \pm 6.45 \%$ \\
\hline 52 weeks & $1246.12 \pm 30.87$ & $45.80 \pm 6.85 \%$ \\
\hline
\end{tabular}

\section{Discussion:}

Periportal hepatic fibrosis caused by schistosomal infestation is a pathology that is different from cirrhosis. Bilharzial patients tend to have good hepatic reserve as compared to cirrhotics. ${ }^{11}$ This might reflect the good hepatocyte perfusion inspite of the periportal fibrosis caused by the immune reaction against the schistosoma eggs.

In the era of liver transplantation, extensive research has been conducted recently to determine the factors responsible for liver regeneration after hepatectomy. ${ }^{12,13}$ The percentage increase of the portal flow to the remaining liver segment seems to be a determining factor that govern the rate of regeneration of the remaining liver. ${ }^{14}$

Coming to the results of the current study, the mean operative blood loss was $430 \pm 720.72 \mathrm{mls}$. This compares favorably with that reported for surgery of normal livers: Clavien et al, who reported 100 resections in normal livers, had a median blood loss of 250 $\mathrm{mL}$ (range $50-5000 \mathrm{~mL}$ ). ${ }^{15}$ The operative time of $155 \pm 73$ minutes was also comparable to that of normal liver resection. 16,17

The percentage increase in liver volume of the studied patients was $17.43 \% \pm 10.53 \%$,
$36.49 \% \pm 6.45 \%$ at 12 and 24 weeks postoperatively. When comparing these values to those reported by Chen et al who found that normal liver increases in volume by $21.2 \pm 6.7 \%$ and $30.6 \pm 12.7 \%$ at 3 and 6 months postresection respectively while cirrhotic livers increase by only $8.5 \pm 3.6 \%$ and $12.9 \pm 4.5 \%$ in the same periods. It is noticeable that the rate of regeneration of bilharzial liver is much closer to that of the normal liver compared to cirrhotic liver. ${ }^{18-20}$

Surgery on cirrhotic liver invites high incidence of complications. Operative complications were found to be significantly higher when comparing cirrhotic with noncirrhotic liver resection. ${ }^{21,22}$ There were no major complications among the studied patients.

\section{References:}

1- Strickland GT: Liver disease in Egypt: Hepatitis C superseded schistosomiasis as a result of iatrogenic and biological factors. Hepatology 2006; 43(5): 915-922.

2- Takahashi T, Malchesky PS, Nose Y: Artificial liver. State of the art. Dig Dis Sci 1991; 36: 1327-1340. 
3- Anthony PP, Ishak KG, Nayak NC, Poulsen HE, Sheuer PJ, Sobin JH: The morphology of cirrhosis: Recommendation on definition, nomenclature and classification by a working group sponsored by World Health Organization. J Clin Pathol 1978; 31: 395414.

4- Okuda K: Non-cirrhotic portal hypertension versus idiopathic portal hypertension. $J$ Gastroenterol Hepatol 2002;17(3): 204213.

5- Farges O, Malassagne B, Flejou JF, Balzan S, Sauvanet A, Belghiti J: Risk of major liver resection in patients with underlying chronic liver disease: A reappraisal. Ann Surg 1999; 229(2): 210-215.

6- Fan ST, Lo CM, Liu CL, Lam CM, Yuen WK, Yeung C, Wong J: Hepatectomy for hepatocellular carcinoma: Toward zero hospital deaths. Ann Surg 1999; 229(3): 322-330.

7- Poynard T, Imbert-Bismut F, Munteanu M, Messous D, Myers RP, Thabut D, Ratziu V, Mercadier A, Benhamou Y, Hainque B: Overview of the diagnostic value of biochemical markers of liver fibrosis (FibroTest, HCV FibroSure) and necrosis (ActiTest) in patients with chronic hepatitis C. Comp Hepatol 2004; 3: 8.

8- Wu CC, Cheng SB, Ho WM, Chen JT, Yeh DC, Liu TJ, P'eng FK: Appraisal of concomitant splenectomy in liver resection for hepatocellular carcinoma in cirrhotic patients with hypersplenic thrombocytopenia. Surgery 2004; 136(3): 660-668.

9- Nagasue N, Kohno H, Tachibana M, Yamanoi A, Ohmori H, El-Assal ON: Prognostic factors after hepatic resection for hepatocellular carcinoma associated with Child-Turcotte class B and C cirrhosis. Ann Surg 1999; 229(1): 84-90.

10-Witte CL, Witte MH, Krone CL: Contrasting hemodynamic patterns of portal hypertension. Ann Surg 1972; 176(1): 68-79.

11-Seyama, Yasuji, Kokudo, Norihiro: Assessment of liver function for safe hepatic resection. Hepatology Research 2009; 39(2): 107-116.
12-Court FG, Wemyss-Holden SA, Dennison AR, Maddern GJ: The mystery of liver regeneration. British Journal of Surgery 2002; 89(9): 1089-1095.

13-Zhang Lisheng, Huang Xiongfei, Meng Zhipeng, Dong Bingning, Shiah Steven, Moore David D, Huang Wendong: Significance and mechanism of CYP7a1 gene regulation during the acute phase of liver regeneration. Molecular Endocrinology 2009; 23(2): 137-145.

14-Sgro JC, Charters AC, Chandler JG, et al: Studies of the site of origin of the hepatotrophic portal blood factor involved in liver regeneration. Surg Forum 1973; 24: 377.

15-Clavien PA, Selzner M, Rudiger HA, Graf R, Kadry Z, Rousson V, Jochum W: A prospective randomized study in 100 consecutive patients undergoing major liver resection with versus without ischemic preconditioning. Annals of Surgery 2003; 238(6): 843-852.

16-Mándli T, Fazakas J, Ther G, Arkosy M, Füle B, Németh E, Fazakas J, Hidvégi M, Tóth S: Evaluation of liver function before living donor liver transplantation and liver resection. Orv Hetil 2008; 149(17): 779786.

17-Polanco P, Leon S, Pineda J, Puyana JC, Ochoa JB, Alarcon L, Harbrecht BG, Geller D, Peitzman AB: Hepatic resection in the management of complex injury to the liver. Journal of Trauma-Injury Infection \& Critical Care 2008; 65(6): 1264-1270.

18-Miin-Fu Chen, Tsann-Long Hwang, ChienFu Hung: Human liver regeneration after major hepatectomy: A study of liver volume by computed tomography. Ann Surg 1991; 213 (3): 227-229.

19-Regimbeau JM, Kianmanesh R, Farges O, Dondero F, Sauvanet A, Belghiti J: Extent of liver resection influences the outcome in patients with cirrhosis and small hepatocellular carcinoma. Surgery 2002; 131(3): 311-317.

20-Michel J, Suc B, Montpeyroux F, Hachemanne S, Blanc P, Domergue J, Mouiel J, Gouillat C, Ducerf C, Saric J, Le Treut YP, Fourtanier G, Escat J: Liver 
resection or transplantation for hepatocellular carcinoma? Retrospective analysis of 215 patients with cirrhosis. Journal of Hepatology 1997; 26(6): 1274-1280. 21-Wu CC, Cheng SB, Ho WM, Chen JT, Liu TJ, P'eng FK: Liver resection for hepatocellular carcinoma in patients with cirrhosis. Br J Surg 2005; 92(3): 348-355. 22-McCormack L, Petrowsky H, Henrik C, Pierre-Alain: Surgical therapy of hepatocellular carcinoma. Eur J Gastroenterol Hepatol 2005; 17(5): 497503. 